\title{
NOTAS
}

\section{La Poesía Mexicana de hoy}

$A$ veces es el bosque el que no nos deja ver los árboles. Es decir: vemos -intuimos- ante nosotros una presencia vasta y confusa, sabemos que una corriente literaria importante existe, vasta, múltiple, ramificada, a nuestro alcance, pero no sabemos por dónde empezar, cuáles son los "árboles literarios" que nos conducirán al centro de la espesura, cuáles son las sendas que vale la pena recorrer antes que otras. Esto suele ocurrir, sobre todo, cuando nos enfrentamos a la poesía de estos últimos diez años en México. La finalidad de un ensayo de exploración como el presente -ensayo forzosamente imperfecto, personal, subjetivo- es precisamente la de abrir caminos, organizar provisionalmente el caos, concentrar la atención en unos cuantos nombres, unas cuantas obras, que por su interés y su impacto artístico nos obliguen -más tarde- a seguir adelante y a explorar con mayor cuidado el conjunto.

Exploración necesaria, urgente: como ha señalado Ramón Xirau, aludiendo a un "bosque literario" todavía más vasto, "la poesía lírica de la América española - y, en general, la poesía escrita en español- es una de las cimas de la literatura occidental en el siglo $\mathrm{xx}$. De los modernistas a los poetas más jóvenes podemos seguir una corriente poética continua, sostenida, que cabe comparar únicamente, dentro de las coordinadas de nuestra literatura, con la de España e Hispanoamérica en los siglos dieciséis y diecisiete, nuestros Siglos de Oro". ${ }^{1}$ Se trata de una poesía abundante y diversa, innovadora y cambiante, de una poesía en movimiento (para describirla con el título de una reciente antología) que parece avanzar simultáneamente en direcciones distintas $y$, a veces, contradictorias. Medir o analizar geométricamente las aguas de un río es tarea imposible, y además inútil. Mejor sumergirse, bucear, sacar a la superficie algunos de los bellos guijarros que brillan en el fondo. Resultan indispensables -antes de entrar en materia-- unas pocas generalidades. Son las siguientes:

1 R. Xirau, Paesia bispanoamericana y españold. México, U.N.A.M., 1961, p. 16 . 
1) Un examen somero de la sociología cultural del México de hoy revela influencias variadas y eclécticas. Por una parte, la creciente presencia de la cultura norteamericana (a partir de la postguerra, y en especial del régimen presidencial de Miguel Alemán, México se convierte, cada vez más, en dependencia económica de Estados Unidos; la capital revela aspectos que no entiende quien no haya vivido en San Juan de Puerto Rico o en Los Angeles de California). Pero sigue activo el influjo de la literatura francesa, y, esporádicamente, la española; se lee, cada vez más, lo publicado por autores hispanoamericanos: Cortázar, García Márquez, Parra, Linh, los cubanos de hoy. Y, finalmente, el influjo de lo mexicano autóctono, precolombino, tanto en las artes plásticas como en literatura, ha dejado de ser retórica o aspiración romántica para convertirse, en unos pocos casos, en fecunda realidad.

2) La poesía mexicana de hoy no es - no podría serlo- diferente, en esencia, de lo que era hace diez, quince, veinte años. Hay cambios de matiz, no cambios radicales. Siguen en aumento la cantidad de lo publicado - y en pocos casos también la calidad- $\mathrm{y}$ el número de lectores. Sin embargo, las cifras de libros publicados y el tiraje de éstos siendo inferiores a las de la novela. La poesía mexicana de hoy sigue siendo un gran banquete con manjares suntuosos para un númeto exiguo de comensales. Los condimentos - surrealismo, existencialismo, poesía comprometida - no dan idea cabal de la refinada y original composición de las obras que se nos of recen. Lo decisivo sigue siendo la visión perso. nal, el individualismo creador de cada poeta.

3) El individualismo creador no excluye la protesta social ante una situación con frecuencia intolerable, casi siempre torpe y absurda, que es la que ofrece la sociedad mexicana - e hispanoamericana- de hoy. Pero los poetas de hoy, a diferencia de lo que ocurría hace una generación - pensemos en Neruda, en Vallejo, en Spencer, Eluard, Alberti, Audenson mucho menos ideológicos, mucho menos amigos de creer en utopías presentes o futuras. No es que hayan perdido la esperanza. Pero saben que el paraiso no. se halla a la vuelta de la esquina, y que la conquista de un mundo mejor no va a resultar empresa fácil.

Imprescindible - inevitable, justo- es referirnos, al principio de un recuento de poetas mexicanos, a Octavio Paz. Nacido en 1914, el mismo año que Nicanor Parra, Paz supera al chileno no solamente en su lenguaje más elástico, sutil y refinado, sino también en la densidad de la ideología que sustenta, como armazón interna e invisible, sus poemas, y le permite también colocarse en el primer plano de los prosistas: crítico de literatura y pintura, historiador, sociólogo, intérprete de Lévi-Strauss, 
definidor de lo oriental, la obra en prosa de Paz es rica y luminosa como pocas. En estos últimos años, y sobre todo a partir de Piedra de sol, la obra poética de Paz parece haber cambiado ligeramente de rumbo y haber llegado a una madurez perfecta. Cabría hablar, como en el caso de Juan Ramón Jiménez, de una "segunda época" de Paz, en la que se cumple plenamente lo que en la primera época estaba ya claramente esbozado y prometido. La poesía de Paz se inicia bajo una doble influencia. Por una parte, la expresión de la soledad y la desesperanza, que alcanza su más alta intensidad en alguno de los mejores poemas de Xavier Villaurrutia y en Muerte sin fin de José Gorostiza. Pero Paz, poeta que se busca a sí mismo a través de otros, une a esta desesperación de sus maestros un sentimiento de solidaridad humana, una violencia revolucionaria que le ayuda a reconocerse en el prójimo, a desdoblarse en el camarada o en la mujer amada. La poesía de soledad, poco a poco, a través de innumerables vicisitudes y amargas caídas, va transformándose - precariamente, provisionalmente- en poesía de la comunión. Piedra de sol es ya el anuncio de que la síntesis "yo-no yo" es posible; más aún; es la meta buscada y deseada. (El romanticismo alemán, en sus dos vertientes complementarias de poesía lírica y de filosofía, es una de las fuentes de Paz.) Se trata, ante todo, de recuperar una unidad perdida, y ello a través del erotismo y también de la palabra:

voy por tu cuerpo como por un mundo, tu vientre es una plaza soleada, tus pechos dos iglesias donde oficia la sangre sus misterios paralelos

(Piedra de sol)

El instante, vivido intensamente, puede convertirse en eternidad:

...el mundo cambia

si dos, vertiginosos y enlazados, caen sobre la yerba...

(ibid.)

Los opuestos pactan: "el poeta", ha escrito Paz, es el hombre que "está enamorado del silencio" y que sin embargo "no tiene más remedio que hablar". Para llegar a "la otra orilla" hay que recorrer un camino dificil, y a veces oscuro: "la poesía moderna es una tentativa por abolir todas las significaciones porque ella misma se presiente como el significado 
último de la vida 8 del hombre". El occidente, frente a la diversidad de opiniones y de visiones, inventa la lógica y el diálogo; Paz, en estos últimos años, trata de superarlos, de eludir el choque entre "el sí y el no", y se vale para ello de su larga experiencia asiática (es Embajador de México en la India de 1960 a 1968), que lo pone en contacto con el budismo y el hinduismo. En Blanco y en Ladera este encontramos los frutos de una evolución profunda. El "blanco" es la unidad de todos los colores, pues los contiene a todos, y es también, al mismo tiempo, el lugar a que llega la flecha bien dirigida. Desde lo alto de su ladera oriental Paz contempla al mismo tiempo lo hindú y lo europeo. A veces parece como si se entablara un diálogo en el interior de cada poema de Paz, y como si el poema, en sus versos finales, fuera la resolución y superación del diálogo con que empezó. Este proceso, visible ya en Salamandra, lo es más en Blanco, poema rico y complicado, y culmina en Ladera este, con su contrapunto entre los poemas cortos, irónicos o "japonesistas", y los largos, místico-erótico-panteistas, impregnados de hinduismo.

Antes de pasar a un grupo de poetas más jóvenes no podemos dejar de mencionar que en la década 1960-70 aparecen obras importantes - recopilaciones, obras completas- de poetas ya maduros, que pertenecen por su formación y su estilo a etapas anteriores. Es el caso de Salvador Novo, siempre ágil y audaz, siempre enfant terrible de las letras mexicanas, especie de Jean Cocteau criollo, que en 1961 da a luz Paesía, en que reúne toda su obra poética; y también de Carlos Pellicer, cuya vasta y rica producción aparece reunida en un libro lujosamente editado, Material poético 1918-1961, publicado en 1962. Tres libros, de Julio Torri, aparece en 1964, si bien recoge materiales escritos bastante antes.

En cuanto al grupo de poetas jóvenes, que maduran en estos últimos diez años, su vitalidad y diversidad hace que sean casi imposibles de "organizar" y clasificar, sobre todo en tan breve espacio. Procedamos, sin embargo, a ordenar en lo posible tan rico caos, sin forzar por ello la esencial originalidad de cada poeta. En primer lugar - ya que antes hemos hablado de Paz- dos poetas pueden ser situados en la misma dirección -amor a la libertad, libertad del individuo y del lenguaje; erotismo que es también altruismo y generosidad. Son Marco Antonio Montes de Oca (n. en 1932) y Homero Aridjis (n. en 1940). El primero es un "poeta nato", espontáneo, variado, verdadero surtidor lírico. En sus últimas obras (Cantos al sol, que no se alcanza, 1961; Fundación del entusiasmo, 1963; La parcela en el Edén, 1964; Vendimia del juglar, 1965; Poesía reunida, suerte de "obras completas" hasta la fecha, 1971) of rece sorpresas, movimiento, vastas imágenes que recuerdan los cuadros de 
Chirico y Tanguy, animado todo por un caleidoscopio interno que estalla y nos proyecta a vastos espacios siderales. Homero Aridjis ( $L a$ difícil ceremonia, 1963; Antes del reino, 1963; Mirándola dormir, 1964; Los espacios azules, 1969) combina el neo-romanticismo, la sensualidad, y el sentido de la magia y el misterio. Su poesía tecuerda a veces los cuadros de Leonora Carrington o de Remedios Varo. Sensualidad que no desemboca en la materia sino en un vacío que es espíritu y transparencia sonora, todo a la vez.

Tomás Segovia (n. 1927; El sol y su eco, 1960; Anagnórisis, 1967) ha traducido a Ungaretti y Rimbaud. Ensayista fino, penetrante, irónico, su personalidad poética es distinta, casi opuesta, a la de su prosa: apasionado y terco en su desolación, en su desamparo de huérfano, sabe expresar el gozo, la alegría de la posesión física y la ternura amorosa: es un gran poeta erótico que busca su identidad en el acto de entrega y sabe encontrar densidad casi metafísica a los gestos del cuerpo humano. Gabriel Zaid (n. 1934; Fábula de Narciso y Ariadne, 1958; Seguimiento, 1964; Campo nudista, 1969) ha leído a Paz y a Pellicer pero ha encontrado su propio estilo, concentrado y lleno de sorpresas, de repeticiones que no lo son del todo, sino más bien ligeras modificaciones, como en su Nacimiento de Venus:

Así surges del agua, blanquísima, y tus largos cabellos son del mar todavía, y los vientos te empujan, las olas te conducen, como el amanecer, por olas, serenísima.

Así llegas helada como el amanecer.

Así la dicha abriga como un manto.

Zaid ha cultivado también el poema en prosa (señalemos de paso que este género, tan poco abundante en la literatura en lengua española, ha encontrado en México, gracias a Juan José Arreola, autor de Confabulario total, un maestro indiscutible, y digno de un estudio aparte).

A diferencia de los cuatro poetas jóvenes ya mencionados, y muy apartado de todo grupo, toda corriente, un solitario -único, inclasificable, amargo, violento, "torpe", lleno de disonancias, indiscutiblemente un gran poeta: es Jaime Sabines, n. en 1925, autor de Diario semanario (1961), Recuento de poemas (1963; contiene varios libros publicados anteriormente), Yuria (1969). Sabines sorprende y arrebata por su violencia lírica, sus hallazgos verbales, su insistencia en los temas de la 
muerte y el amor -renovándolos ambos, cosa que parece imposible. Su elegía a la muerte de su padre, "Algo sobre la muerte del mayor Sabines", resiste la comparación con las elegías de Jorge Manrique y Federico García Lorca.

José Emilio Pacheco (n. 1939) es todo lo contrario de un solitario: crítico alerta y bien informado, es uno de los centros nerviosos de la cultura mexicana de hoy. En Los elementos de la nocbe (1963) y El reposo del fuego (1966) desarrolla un estilo severo y preciso: nada falta, no sobra nada. Sus poemas en prosa son tensos, redondos, cerrados sobre sí mismos, pero disparan de pronto una pregunta -o una respuestaque nos sobrecoge. Su ironía - a veces seca, amarga; otras veces alegre, como un juguete- es uno de sus rasgos principales. Dos ejemplos: "Autoanálisis",

He cometido un error fatal

$-\mathrm{y}$ lo peor de todo-

es que no sé cuál

y "Ya todos saben para quién trabajan":

Traduzco un artículo de Esquire

sobre una hoja de Kimberly-Clark Corp.,

en una antigua máquina Remington.

Corregiré con un bolígrafo Esterbrook.

Lo que me paguen aumentará en unos cuantos pesos las arcas

de Carnation, General Foods, Heinz,

Colgate-Palmolive, Gillette

y California Packing Corporation.

Otros poemas - como el dedicado a la muerte del Che Guevara - revelan un tono elegíaco contenido, discreto, controlado por la inteligencia - y la rabia- del hombre racional que coexiste con el animal poético en Pacheco. Su mejor libro es, creemos, el último, No me preguntes cómo pasa el tiempo, publicado en 1969. Ironía y ternura se funden, dan como síntesis un patetismo rebelde y descarnado para el que haria falta un nombre nuevo.

Ahcra bien: como todo lector espera una visión hasta cierto punto ordenada, creo prudente señalar algunas líneas ordenadoras, líneas de fuerza. Organizadas en torno a un eje, o mejor un poeta jánico, Sabines, the puede funcionar en varias direcciones. Los poetas jóvenes mencio- 
nados antes de Sabines serían poetas ante todo líricos, subjetivos, intensamente personales. Los que mencionaremos después de Sabines - Pache. co, y, además, Jaime Labastida, Rubén Bonifaz Nuño, Rosario Castellanos, Oscar Oliva, Jaime Augusto Shelley, Sergio Mondragón- sin dejar de ser personales, líricos, subjetivos, muestran una sensibilidad especial frente a fenómenos sociales, colectivos. Lo mismo ocurre con Jesús Arellano, el autor de Vía libre. ¿Poesía comprometida? La etiqueta nada dice. La poesía siempre está comprometida, con algo, con alguien. Hay fenómenos - la revolución cubana, el desamparo de los pobres en Latino. américa, la incesante crueldad y ceguera de los gobiernos, o, como diría Moreno Villa, "la pobretería y la locura"- que se imponen - a veces bruscamente- a la sensibilidad de un poeta. A veces el poeta se sabe rodeado de voces amigas. Entonces se produce el fenómeno - raro pero digno de aplauso- del libro colectivo. Así, por ejemplo, Juan Bañuelos, poeta de innegable talento, se convierte en el espíritu animador de todo un grupo, y publica La espiga amotinada en 1959 (libro colectivo precedido. de un certero prólogo de Agustí Bartra) en compañía de Jaime Shelley, Jaime Labastida, Oscar Oliva y Eraclio Zepeda. Insiste en 1965 con Ocupación de la palabra, acompañado, una vez más, por los cuatro poetas ya mencionados. En general sus poemas, los de Labastida y los de Zepeda son los mejores del grupo. Grupo apasionado, que cree con fervor en un cambio profundo que habrá de llegar muy pronto, pero sabe cantar también la cólera, la indignación, la rabia frente a los errores del presente. La belleza será convulsiva o no será, proclamaban los surrealistas. Para este grupo, la convulsión ha de ser revolucionaria. Tras el mensaje $-\mathrm{y}$ a veces la propaganda- se encuentran no pocas veces poemas de una pasión personal, subjetiva, que el idealismo abre hacia lo colectivo: cuando "funcionan" adquieren un tono épico difícil de igualar. No siempre "funcionan".

Claro está que -como observaba Mallarmé- la poesía no se hace con ideas, sino con palabras. O por lo menos las ideas, por sí solas, no bastan. La técnica poética, con frecuencia, es el mensaje poético. Por ello vale la pena cerrar este breve esquema oponiendo el estilo de dos poetas "virtuosos", "técnicos" al de dos poetas relativamente sencillos y directos. De los dos "técnicos", uno es un poeta conocido y justamente famoso, Rubén Bonifaz Nuño. El otro, más joven, apenas empieza a publicar: Gerardo Deniz, cuyo primer libro, Adrede, apareció en 1970. Los dos poetas "sencillos" son ambos bien conocidos: Rosario Castellanos y Jaime García Terrés. 
Rubén Bonifaz Nuño, n. en 1923, humanista, profesor de latín y traductor de clásicos, es poeta culto, capaz de escribir en cualquier metro, de dominar el lenguaje hasta sus raíces. En Imágenes domina lo clásico; en los demonios y los días y Fuego de pobres (1961.), el tema social; en El manto y la corona el tema del amor; en Siete de espadas (1966) el elemento prehispánico, siempre equilibrado, fundido, vivificado por el rigor clásico:
Escalera de torre, puerta;
sangre de parto en la mañana oscura.
$\mathrm{Y}$ águilas migratorias parten,
canta una tribu, una ciudad se funda;
luchan pueblos nupciales; se congrega
el imperio del sol: en el espejo
que en tu vientre nace cuando duermes.

(Siete de espadas, p. 7)

Bonifaz Nuño es casi un "poeta profesional", "oficial", "poeta laureado" (ha ganado innumerables juegos florales). Sabe su oficio; todo lo que" escribe tiene cierta calidad, un tono elegante, un lenguaje preciso y expresivo. Y es, con frecuencia, un gran poeta. Frente a este "Establishment" poético que es Bonifaz Nuño, el otro "técnico" que hemos mencionado, Gerardo Deniz, es casi un principiante. Su técnica es diferente, más científica que clásica (Adrede es un libro muy difícil; nos hace pensar en un Borges que escribicra en sueños o en trance y cuyo mensaje nos llegara medio borrado; las alusiones biológicas, zoológicas, o de otras clases, nos obligan constantemente a consultar el diccionario o la enciclopedia.) Es, además, un gran maestro de la aliteración, porque sí, por el placer de jugar con las palabras y los sonidos:
A la ropa sobaba la solapa, era sebo y sapos su sed. Selim el rajá se sonrió: ¡Salam! ¡sal a reconocer a las malas! Oírnos es ajarle miles de sus sopas; yo besaré a palos a la babosa, ¡por Alả!

("De vuelta a las palabras")"

- Publicado por La Gaceta, revista del Fondo de Cultura Económica, núm. 3, marzo 1971. 
$\mathrm{Y}$ ahora, para terminar, dos poetas "sencillos". Lo cual no significa que no sean cultos. Rosario Castellanos, n. en 1925, sabe expresar su intimidad, su complejidad agridulce, amorosa y desolada, en forma clara y directa - su arte consiste en esconder la técnica. $Y$ va evolucionando hacia una sencillez cada vez mayor, desde su primer libro, Trayectoria del polvo, pasando por Poemas, Livida luz (1960) y sus últimas producciones, como el poema que insertamos, último que conocemos de ella:

\section{Valium 10}

A veces (y no trates

de restarle importancia

diciendo que no ocurre con frecuencia)

se te quiebra la vara con que mides,

se te extravía la brújula

y ya no entiendes nada.

El dia se convierte en una sucesión

de hechos incoherentes, de funciones

que vas desempeñando por inercia y por hábito.

$\mathrm{Y}$ lo vives. $\mathrm{Y}$ dictas el oficio

a quienes corresponda y das la clase

lo mismo a los alumnos inscritos que al oyente $y$ en la noche redactas el texto que la imprenta devorará mañana.

$\mathrm{Y}$ vigilas (oh, sólo por encima)

la marcha de la casa, la perfecta coordinación de múltiples programas

(porque el hijo mayor ya viste de etiqueta para ir de chambelán a un baile de quince años y el menor quiere ser futbolista y el otro tiene un poster del Che junto a su tocadiscos).

$Y$ repasas las cuentas del gasto y examinas junto a la cocinera, el menú semanario.

$Y$ aún tienes voluntad para desmaquillarte y ponerte la crema nutritiva y aún leer algunas líneas antes de consumir la lámpara. 
$Y$ ya en la oscuridad, en el umbral del sueño, echas de menos lo que se ha perdido:

el diamante de más precio, la carta

de marear, el libro

con cien preguntas básicas (y sus correspondientes

respuestas) para un diálogo

elemental siquiera con la Esfinge.

$\mathrm{Y}$ tienes la penosa sensación

de que en el crucigrama se deslizó una errata

que lo hace irresoluble.

$\mathrm{Y}$ deletreas el nombre del Caos. Y no puedes

dormir si no destapas

el frasco de pastillas y si no tragas una

en la que se condensa,

químicamente pura, la ordenación del mundo.

Jaime García Terrés, n. en 1924, buen conocedor de los clásicos - y de los poetas ingleses y norteamericanos- puede, en sus crónicas y ensayos breves en prosa (por ejemplo, en La feria de los días) ser irónico, mordaz, amargo. Su poesía es diferente, más lisa y sobria, aunque algunos de los temas de la prosa - la responsabilidad, la fidelidad, la atención al presente, a lo cotidiano, a lo en apariencia pequeño, pero que se trata de salvar, de insertar en un conjunto mucho más vasto- sean los mismos que los que aparecen en sus libros de poesía, Las provincias del aire (1956), la fuente oscura (1961), Los reinos combatientes (1961), Todo lo más por decir (de próxima publicación). Lenguaje culto, pero sin exceso; conciso, epigramático a veces. Se trata de "salvar las apariencias", en el sentido de elevar lo cotidiano poniéndolo en tensión, conectándolo con el destino del hombre, como, por ejemplo, en "Funerales", parte de su último libro, aún inédito:

Pides que me levante. No podré.

Tengo las manos y los pies raídos y un féretro de pino por encierro.

Lo sé, lo sé, las puertas de la casa ya no sirven, igual que las ventanas, es preciso pintar los cuatro muros, cortar la yerba que se arremolina; hace falta dinero para todo. 
Pero se me han podrido las pupilas, los dedos, vastas porciones de mi cuerpo, y pronto perderé los demás.

Quizá, también, lo mismo que se propone Rosario Castellanos. O lo que se proponen los demás poetas del México de hoy. Conectar el presente de hoy - caótico, no siempre bello- con un universo mucho más vasto. Cada uno establece puentes a su manera. Con más o menos fortuna. Entre todos ellos dan a nuestro presente una dimensión nueva, más completa, más expresiva y ennoblecedora.

Yale University.

MANUEL DURÁN 
